\title{
Author Correction: Cell-type-dependent histone demethylase specificity promotes meiotic chromosome condensation in Arabidopsis
}

Jun Wang (i), Chaoyi Yu(D), Shuaibin Zhang, Juanying Ye, Hang Dai, Hongkuan Wang, Jiyue Huang (i), Xiaofeng Cao (D),

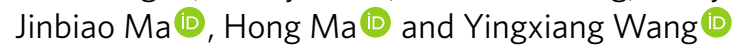

Correction to: Nature Plants https://doi.org/10.1038/s41477-020-0697-0, published online 22 June 2020.

In the version of this Article originally published, the first name of the author Shuaibin Zhang was misspelled as 'Shuaibing. This has now been corrected.

Published online: 28 July 2020

https://oi.org/10.1038/s41477-020-00755-3

๑ The Author(s), under exclusive licence to Springer Nature Limited 2020 